\title{
EFFECTS OF PLASMOQUIN, ATEBRIN, AND QUININE ON THE ELECTROCARDIOGRAM
}

\author{
BY \\ H. L. HEIMANN AND B. G. SHAPIRO \\ From the Oribi Military Hospital, South Africa \\ Received April 21, 1943
}

Our attention was drawn to the changes in the electrocardiogram during the administration of plasmoquin, by the fact that leads IV R and IV F showed changes of the coronary type in a soldier, agend twenty-two, who complained of præcordial pain while receiving this drug. While we have seen several cases of indisputable coronary thrombosis in soldiers of about this age coming from the Middle East, the clinical picture in this man did not warrant the diagnosis. We were, therefore, led to wonder if the plasmoquine could not be responsible for this type of curve. As this patient had also had atebrin and quinine a short time previously, it was necessary to examine the effect of all these drugs on the cardiogram.

At this time, there were a number of men in the hospital who were convalescent from malaria and needed courses of these medicaments against relapses. They were in a reasonably good state of health as the malaria had been contracted six or more weeks previously, and they had been apyrexial for about four weeks. None were grossly anæmic, so no abnormal cardiographic findings were to be anticipated as a result of malaria itself at this stage of convalescence-if, indeed, malaria does cause such changes at any stage, and we have not found any reference to such changes.

A series of six men were first investigated. They had had various of these anti-malarial drugs in previous months. When the effect on the case mentioned above was noticed, cardiograms were taken in these six and they were then put on plasmoquine for one week $(1 / 6$ grain b.i.d.). At the end of this period a second cardiogram was taken. All drugs were then omitted for a week, when a third cardiogram was taken. They were then put on to atebrin 1.5 grains, t.i.d., for a week, and a fourth record was taken. As time was pressing, they were not given a rest period, but were immediately put on quinine for six days, the dose varying from 5 to 10 grains, t.i.d. A fifth record was then taken.

Owing to shortage of bromide paper, our observations were made principally on the chest leads, for in them the changes seemed most marked. Leads IV R and IV F were used, as defined by the joint British and American committees on præcordial leads.

\section{FINDINGS \\ Plasmoquin}

$P$ wave. There was some increase in amplitude, mainly in lead IV $R$.

P-R interval. No effect was observed.

QRS wave. The effect was variable on $\mathrm{Q}$, but generally there was an increase in amplitude in lead IV R and no effects in IV F. No definite effect on $R$ was observed. The effect on $S$ was variable and it was generally increased in amplitude, even up to double, in leads IV $R$ and IV F.

$T$ wave. This was increased in amplitude up to double in leads IV $R$ and IV F. 
S-T segment. In several cases this became elevated, sometimes being bowed with the convexity downwards (Fig. 1 A). These elevated curves simulate those of coronary thrombosis. Later the segment becomes a steep rising one to the increased T wave. (See Fig. 1 B).
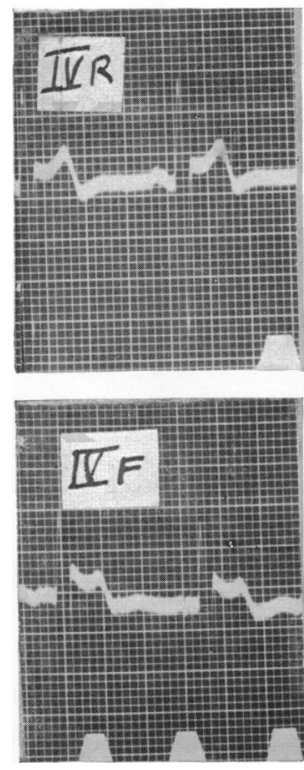

A
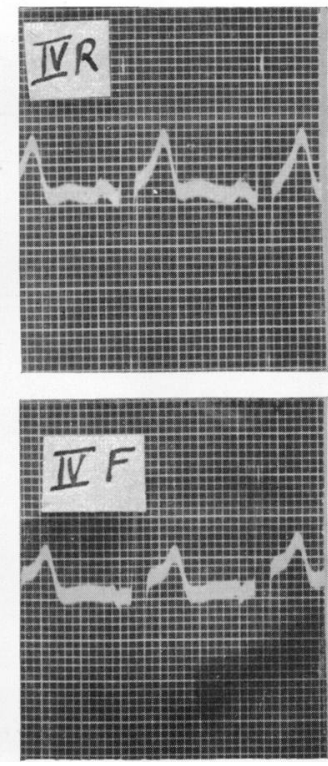

B
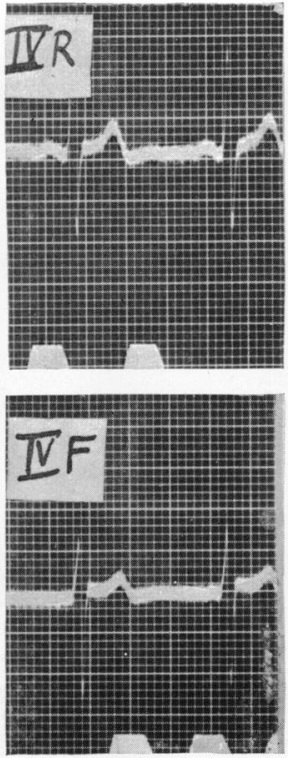

$\mathrm{C}$
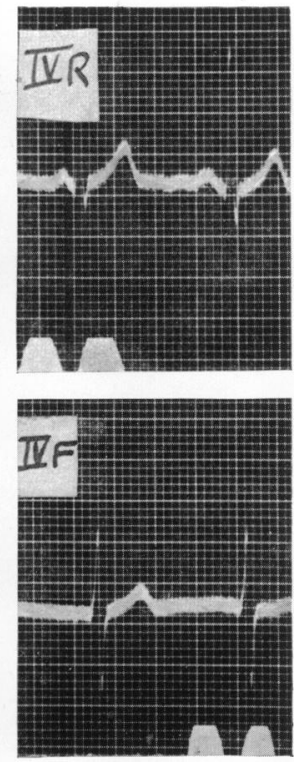

$\mathrm{D}$

Fig. 1.

(A) Effect of plasmoquin on the electrocardiogram. The patient was taking $1 / 6$ grain, b.i.d.

(B) Effect of plasmoquin, 1/6 grain, b.i.d., for 7 days.

(C) Effect of atebrin, 1.5 grains, b.i.d., for 7 days.

(D) Effect of quinine, 7 grains, b.i.d., for 5 days. All these figures are from the same patient.

\section{Atebrin}

$\mathrm{P}$ wave. This was generally decreased, sometimes to half the previous size in lead IV R. $\mathbf{P}-\mathbf{R}$ interval. This was unaffected.

$\mathrm{QRS}$ wave. The $\mathrm{Q}$ wave may be increased in amplitude; the $\mathrm{R}$ and $\mathrm{S}$ waves were generally decreased in amplitude.

T wave. This was markedly depressed in all cases, and sometimes in leads IV R and IV F, by as much as 70 per cent of normal (Fig. $1 \mathrm{C}$ ).

$\mathrm{S}-\mathrm{T}$ segment. Atebrin restored this to iso-electric level after elevation by plasmoquin.

\section{Quinine}

$\mathbf{P}$ wave. This was decreased, but not to the extent seen in the atebrin effect.

P-R interval. No effect.

QRS and S-T. There was no constant effect on Q or on the S-T segment, but R and S were decreased in amplitude in both IV R and IV F (Fig. $1 \mathrm{D})$.

T wave. This was markedly decreased, though less than by atebrin. Often a small negative phase followed the initial positive phase.

\section{SUMMARY}

The effects of plasmoquin, atebrin, and quinine on the electrocardiogram of convalescent malarial patients has been investigated.

Plasmoquin increases the amplitude of the various deflections, affecting the $\mathrm{T}$ wave most 
markedly and constantly. In some cases the most striking feature is the effect on the S-T segment which simulates the cardiogram of coronary thrombosis. Whether this is due to an effect on the coronary circulation, we are not in a position to state.

Atebrin decreases the amplitude of the various deflections, also affecting the $\mathrm{T}$ wave most markedly and constantly. It restores the $\mathrm{S}-\mathrm{T}$ segment to the iso-electric level after it has been elevated by plasmoquin.

Quinine has an effect similar to atebrin but to a lesser degree.

Differentiation between the effects of plasmoquin on the one hand, and of atebrin and quinine on the other, in a particular patient may be made on the cardiographic findings given above. Plasmoquin increases the size of the $T$ wave above normal while quinine and atebrin decreased it below normal. Plasmoquin often has an effect on the S-T segment, as described ; this is not seen in the exhibition of either of the other two drugs. 